\title{
A Combination of Antigen Retrieval Methods Significantly Enhances the Unmasking of Tedious Antigens of Lymphangiogenesis and Angiogenesis in Canine Mammary Tumour
}

\author{
Parmeet Pal Singh*, Naresh Kumar Sood \\ Department of Veterinary Pathology, College of Veterinary Science, Guru Angad Dev Veterinary and Animal Sciences University, \\ Ludhiana, India \\ Email: *drppsingh1986@gmail.com
}

How to cite this paper: Singh, P.P. and Sood, N.K. (2017) A Combination of Antigen Retrieval Methods Significantly Enhances the Unmasking of Tedious Antigens of Lymphangiogenesis and Angiogenesis in Canine Mammary Tumour. Journal of Biosciences and Medicines, 5, 44-55. https://doi.org/10.4236/jbm.2017.512006

Received: October 16, 2017

Accepted: December 2, 2017

Published: December 5, 2017

Copyright $\odot 2017$ by authors and Scientific Research Publishing Inc. This work is licensed under the Creative Commons Attribution International License (CC BY 4.0).

http://creativecommons.org/licenses/by/4.0/

\begin{abstract}
The use of immunohistochemical techniques has enhanced the diagnostic intensities in pathology. The sensitivity and specificity of any immunohistochemical protocol mainly depends on the ability to unmask antigen from formalin fixed tissue. Various combinations of antigen retrieval protocols have been used to unmask antigen efficiently but none has been established as a flawless one. These protocols either have one or the other lacunae, lacking repeatability under same conditions. In our study, we tried to develop a standardized immunohistochemical protocol for the identification of blood and lymphatic vessels in tissue sections of canine mammary tumour (CMT) using recently identified markers. The combined effects of antigen retrieval (AR) methods including $\mathrm{pH}$ shock by Heat-induced epitope retrieval (HIER) and Protease-induced epitope retrieval (PIER) were found highly effective in retrieval of tedious antigens of lymphangiogenesis and angiogenesis. The use of combined antigen retrieval technique for the unmasking of antigens from over fixed, old formalin fixed paraffin embedded (FFPE) canine mammary tumour sections resulted in efficient unmasking of epitopes when compared with the individual antigen retrieval methods.
\end{abstract}

\section{Keywords}

Angiogenesis, Antigen Retrieval, Canine Mammary Tumour, Immunohistochemistry, Lymphangiogenesis

\section{Introduction}

Growing interest in immunohistochemical procedure has led to the develop- 
ment of a wide range of highly specific immuno-stains, thus offering a greater role in pathological investigative studies [1]. Till now, the biggest deficiency in immunohistochemistry has been how to maintain both good morphology and the immuno-reactivity of antigens in tissue sections. Various techniques of unmasking and retrieving the antigens from tissue section have revolutionized the patho-clinical diagnosis and have played a pivotal role in enabling immunohistochemistry as a major diagnostic tools in case of formalin-fixed, paraffin-embedded tissues [2]. Antigen Retrieval (AR) techniques are aimed at significantly increasing the sensitivity of the immunohistochemical detection of epitopes in addition to better morphologic details and more precise antigen localization [3] [4].

The antigen can be unmasked or retrieved by physical, chemical approaches or by mixture of both [5]. In general, the principle of antigen retrieving involves the breaking of protein cross-links, introduced by formaldehyde fixation process, with the subsequent exposition of antigen sites to antibody [6].

AR procedures offer additional advantages such that with the lowering of the threshold for detection of antigens, it allows the use of higher antibody dilutions, which offers economic advantage, lowers the possibility of background staining, and increases the labelling specificity. Furthermore, antigen retrieval, minimizing the occurrence of false negative results, thus raises the reproducibility of results and, adds to diagnostic accuracy [5] [7].

During the IHC, most of the antibodies require AR which is commonly done either by using citrate or EDTA. A universal antigen retrieval solution is not available [8] [9]. In some instances, for the same antibody citrate had been used for AR [10] [11] [12] [13], while in few EDTA had been used for AR [14] [15] [16]. In few other cases, in addition to citrate or EDTA treatment, enzymatic retrieval has also been used [11] [13] [17]. But there has been no standardized protocol established so far for the antigen retrieval so far.

Standardization of IHC still remains a great challenge. The failure of antibodies to immunostain tissues does not necessarily reflect the absence of epitopes. Lack of, or reduced, immunostaining can be accredited either to the inability of the antibody to reach and recognize the epitope or due to variable conditions of fixation and tissue processing [18].

The aim of the present study was to develop a standardized immunohistochemical protocol for the identification of blood and lymphatic vessels in CMTs which can further substantiate to be beneficial in devising anti-angiogenic and anti-lymphangiogenic therapy for management of CMT. In the present study, we tried combinations of AR methods including $\mathrm{pH}$ shock by Heat-induced epitope retrieval (HIER) and Protease-induced epitope retrieval (PIER) for retrieval of tedious antigen of lymphangiogenesis and angiogenesis and found highly encouraging results for retrieval of antigens from longstanding formalin fixed samples.

\section{Materials and Methods}

\subsection{Source of Samples}

The present study was conducted on tissue samples of 45 confirmed cases of 
CMT available in the Department of Veterinary Pathology, College of Veterinary Science, Guru Angad Dev Veterinary and Animal Sciences University, Ludhiana, Punjab, India. These cases were presented to the Small Animal Clinics of the Department of Teaching Veterinary Clinical Complex, Guru Angad Dev Veterinary and Animal Sciences University, Ludhiana.

\subsection{Histopathology}

After fixation in $10 \%$ neutral buffered formalin, the tissue samples were processed and stained with routine $\mathrm{H} \& \mathrm{E}$ technique [19]. Multiple haematoxylin and eosin (H \& E) stained tissue sections from various sites in each case were screened for the presence of lymphatic's and blood vessels.

\subsection{Immunohistochemistry}

For immunohistochemistry, 4 - $5 \mu \mathrm{m}$ thick paraffin embedded tissue sections were cut and collected on Superfrost/Plus, positively charged microscopic slides (Fisher Scientific, USA) and immunohistochemical staining was performed by using ImmPACT ${ }^{\mathrm{TM}}$ DAB Peroxidase Substrate Kit (Vector Laboratories, Burlingame CA USA). The sections were de-waxed and rehydrated by dipping in EZ-AR ${ }^{\mathrm{TM}}$ Common Solution (BioGenex Laboratories Inc., San Ramon, California, USA), and heating at $70^{\circ} \mathrm{C}$ for 10 minutes in EZ-Retriever ${ }^{\mathrm{TM}}$ System (BioGenex Laboratories Inc., San Ramon, California, USA) and subsequent AR was performed by heat using EZ-AR3 Solution (BioGenex Laboratories Inc., San Ramon, California, USA) and later in EDTA buffer for $10 \mathrm{~min}$ each at $95^{\circ} \mathrm{C}$ (Table 1).

Following AR the sections were allowed to cool and brought to room temperature and were given three washings in $\mathrm{PBS}$ ( $\mathrm{pH} 7.2$ - 7.4) for 3 minutes each. Sections were encircled with hydrophobic pen. The endogenous peroxidase was quenched with a solution of $3 \% \mathrm{H}_{2} \mathrm{O}_{2}$ in methanol for $15 \mathrm{~min}$ at room temperature in humid chamber, followed by thrice washing with PBS for 3 min each. The sections were then incubated with ready to use power block (BioGenex Laboratories Inc., San Ramon, California, USA) to block non-specific protein binding for $15 \mathrm{~min}$ at room temperature in a humidified chamber. Afterwards, the sections were incubated with primary antibodies (Table 2) for 60 minutes at

Table 1. Methods used for epitope retrieval for immunohistochemical staining.

\begin{tabular}{|c|c|c|c|c|}
\hline Sr. No & Name of AR solution used & Dilution used & Temp. \& Time & Use \\
\hline 1. & $\begin{array}{c}\mathrm{EZ}-\mathrm{AR}^{\mathrm{TM}} 3 \text { is a citra based } \\
\text { solution ( } 10 \mathrm{X} \text { Concentrated) }\end{array}$ & $\begin{array}{l}\text { Ten-fold dilution in deionized water } \\
\qquad(\mathrm{pH} 6.0)\end{array}$ & $95^{\circ} \mathrm{C}$ for $10 \mathrm{~min}$ & HIER \\
\hline 2. & Tris EDTA solution & $\begin{array}{l}\text { Prepared by mixing Tris- } 6.2 \mathrm{~g} \text { and } \\
\text { EDTA- } 0.75 \mathrm{~g} \text { in } 1000 \mathrm{ml} \text { of distilled } \\
\text { water }(\mathrm{pH}-9.0)\end{array}$ & $95^{\circ} \mathrm{C}$ for $10 \mathrm{~min}$ & HIER \\
\hline 3. & Pepsin & $2.5 \mathrm{mg} / \mathrm{ml}$ of deionized water & $37^{\circ} \mathrm{C}$ for $3 \mathrm{~min}$ & PIER \\
\hline
\end{tabular}


Table 2. Antibodies used for demonstration of lymphangiogenesis and angiogenesis in CMT.

\begin{tabular}{crrccc}
\hline Sr. No. & $\begin{array}{c}\text { Name of the } \\
\text { antibody }\end{array}$ & Company & $\begin{array}{c}\text { Immuno } \\
\text { globulin class }\end{array}$ & Dilution used & Antigen retrieval \\
\hline 1. & VEGF-D $^{\mathrm{a}}$ & GeneTex International Corporation Taiwan & IgG & $1: 50$ & AR-3 \& Tris EDTA solution \\
2. & VEGFR-3 $^{\mathrm{a}}$ & GeneTex International Corporation Taiwan & IgG & Ready to use & AR-3 \& Tris EDTA solution \\
3. & Podoplanin $^{\mathrm{a}}$ & GeneTex International Corporation Taiwan & IgG & $1: 50$ & AR-3 \& Tris EDTA solution \\
4. & PROX 1 $^{\mathrm{a}}$ & Abgent Flanders Court, San Diego, CA & IgG & $1: 50$ & AR-3 \& Tris EDTA solution \\
5. & LYVE-1 $^{\mathrm{a}}$ & Novus Biologicals, Southpark Way Littleton, CO USA & IgG & $1: 50$ & AR-3 \& Tris EDTA solution \\
6. & Laminin $^{\mathrm{b}}$ & Novus Biologicals, Southpark Way Littleton, CO USA & IgG & $1: 100$ & AR-3, Tris EDTA solution \& Pepsin \\
7. & VEGFR-2 $^{\mathrm{b}}$ & Novus Biologicals, Southpark Way Littleton, CO USA & IgG & $1: 500$ & AR-3 \& Tris EDTA solution \\
8. & VEGF-C $^{\mathrm{a}}$ & GeneTex International Corporation Taiwan & IgG & $1: 25$ & AR-3 \& Tris EDTA solution \\
\hline
\end{tabular}

alymphangiogenetic marker; ${ }^{b}$ angiogenetic marker.

room temperature in humidified chamber.

\section{Results}

The use of single retrieval buffer, most commonly recommended for carrying out immunohistochemistry i.e. citrate buffer ( $\mathrm{pH}$ 6.0) did not yielded any significant results in antigen unmasking and most of the sections as stained with the antibodies directed against podoplanin, LYVE-1, PROX 1, VEGFR-3, VEGFR-2, laminin, VEGF-D and VEGF-C were either negative or mild in intensity. But when the citrate treatment was followed by AR in Tris-EDTA ( $\mathrm{pH} 9.0$ ) buffer, a significant increase in the intensity as well as positivity for the above mentioned markers was observed except for VEGF-C and laminin. In addition to this, another combined treatment of antigen retrieval comprising of citrate, Tris-EDTA and pepsin resulted in complete loss of morphological details except for laminin.

The increase in positivity and intensity with a treatment of citrate followed by Tris-EDTA was seen for podoplanin, LYVE-1, PROX 1, VEGF-D, VEGFR-3 and VEGFR-2. However, the treatment of citrate followed by Tris-EDTA has a deleterious effect on the tissue as tissue gets off the slide due to extreme $\mathrm{pH}$ shock. No increase in intensity or positivity was seen when treatment of citrate and Tris-EDTA was carried out for laminin, but additional treatment with pepsin for 3 minutes at $37^{\circ} \mathrm{C}$ yielded more desirable and good results. VEGF-C marker did not show any reactivity with any of the above used protocols.

The comparison of these three different techniques for AR (Table 3) i.e. use of citrate alone [Figure 1(a), Figure 2(a), Figure 3(a), Figure 4(a), Figure 5(a), Figure 6(a), Figure 7(a), Figure 8(a)]; citrate and Tris-EDTA [Figure 1(b), Figure 2(b), Figure 3(b), Figure 4(b), Figure 5(b), Figure 6(b), Figure $7(\mathrm{~b})$, Figure 8(b)]; citrate, Tris-EDTA and pepsin [Figure 1(c), Figure 2(c), Figure $3(c)$, Figure 4(c), Figure 5(c), Figure 6(c), Figure 7(c), Figure 8(c)] revealed that, for markers viz. Podoplanin [Figure 1(b)], LYVE-1 [Figure 2(b)], PROX 1 [Figure 3(b)], VEGFR-3 [Figure 4(b)], VEGF-D [Figure 5(b)] and VEGFR-2 
[Figure 7(b)], both citrate and Tris-EDTA AR are very effective in unmasking the epitope against these antibodies in canine mammary tumour whereas for laminin marker, in addition to citrate and Tris-EDTA treatment, pepsin reaction is essential to unmask antigen and thus enhance reactivity and increase intensity [Figure 6(c)].

Table 3. Comparison between the three techniques of AR from 45 samples of CMT.

\begin{tabular}{|c|c|c|c|c|c|c|}
\hline $\begin{array}{l}\text { Name of the } \\
\text { antibody }\end{array}$ & $\begin{array}{l}\text { Number of positive } \\
\text { samples with citrate } \\
\text { treatment only }\end{array}$ & $\begin{array}{l}\% \text { age of positive } \\
\text { samples with citrate } \\
\text { treatment only }\end{array}$ & $\begin{array}{l}\text { Number of positive } \\
\text { samples with citrate } \\
\text { and Tris-EDTA } \\
\text { treatment }\end{array}$ & $\begin{array}{c}\% \text { age of positive } \\
\text { samples with citrate } \\
\text { and Tris-EDTA } \\
\text { treatment }\end{array}$ & $\begin{array}{c}\text { Number of positive } \\
\text { samples with citrate, } \\
\text { Tris-EDTA and } \\
\text { pepsin treatment }\end{array}$ & $\begin{array}{l}\% \text { age of positive } \\
\text { samples with citrate, } \\
\text { Tris-EDTA and } \\
\text { pepsin treatment }\end{array}$ \\
\hline VEGF-D & 3 & 6.67 & 33 & 73.33 & 0 & 0 \\
\hline VEGFR-3 & 6 & 13.33 & 39 & 86.67 & 0 & 0 \\
\hline Podoplanin & 10 & 22.22 & 40 & 88.89 & 0 & 0 \\
\hline PROX 1 & 8 & 17.78 & 25 & 55.56 & 0 & 0 \\
\hline LYVE-1 & 5 & 11.11 & 28 & 62.22 & 0 & 0 \\
\hline Laminin & 0 & 0 & 0 & 0 & 39 & 86.67 \\
\hline VEGFR-2 & 5 & 11.11 & 40 & 88.87 & 0 & 0 \\
\hline VEGF-C & 0 & 0 & 0 & 0 & 0 & 0 \\
\hline
\end{tabular}

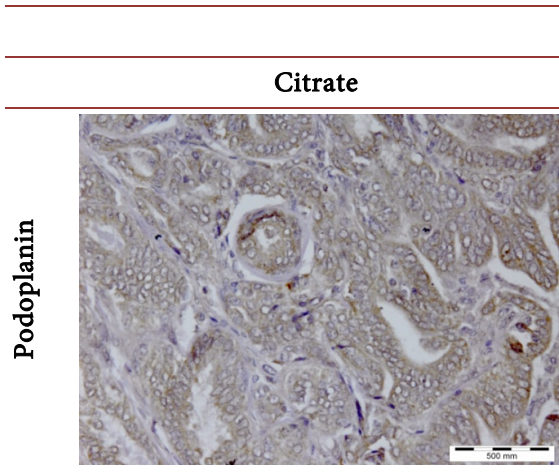

Figure 1(a). Slight cytoplasmic immuno-reactivity for podoplanin in invading tumour cells for podoplanin in CMT when cancer cells in CMT when treated with citrate treated with citrate followed by Tris-EDTA AR alone. Original magnification $\times 400 x$.

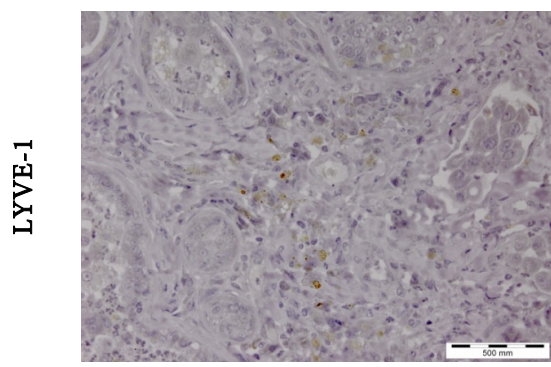

Figure 2(a). Slight cytoplasmic immune-reactivity for LYVE-1 in invading cancer cells when treated with citrate AR alone. Original magnification $\times 400 x$.
AR. Original magnification $\times 400 x$.

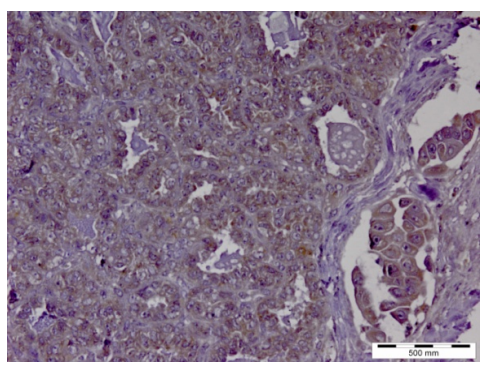

Figure 2(b). Marked immuno-staining of with citrate followed by Tris-EDTA AR. Original magnification $\times 400 x$.

\section{Citrate followed by Tris-EDTA and pepsin}

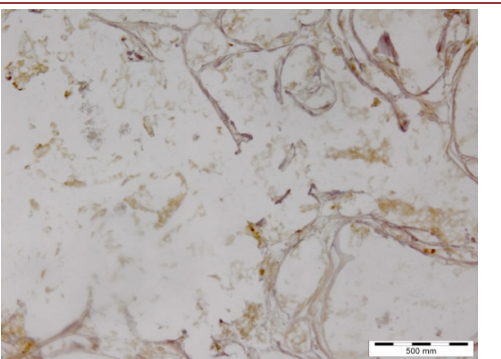

Figure 1(c). Loss of cellular details in CMT for podoplanin when subjected to citrate, followed by Tris-EDTA and pepsin treatment. Original magnification $\times 400 \mathrm{x}$.

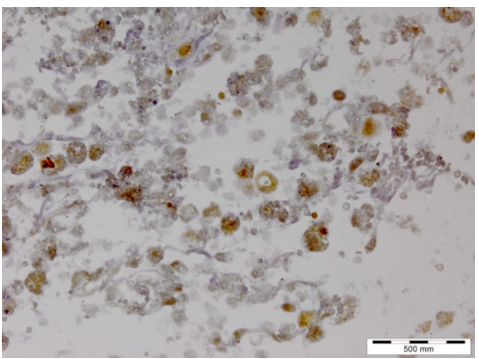

Figure 2(c). Loss of most of the cellular details for LYVE-1 when subjected to citrate, followed by Tris-EDTA and pepsin treatment. Original magnification $\times 400 x$. 


\section{Continued}

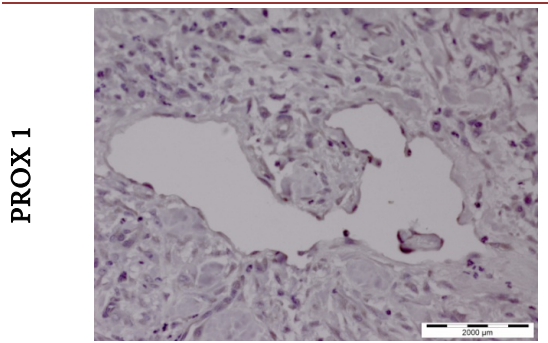

Figure 3(a). Mild nuclear staining of intratumoral lymphatics with PROX 1 when treated with citrate AR alone. Original magnification $\times 1000 \mathrm{x}$.

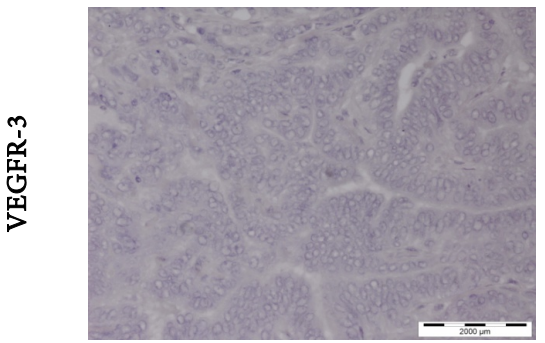

Figure 4(a). Very mild immuno-staining of tumour cells in intratumoral area with VEGFR-3 when treated with citrate AR alone. Original magnification $\times 1000 x$.

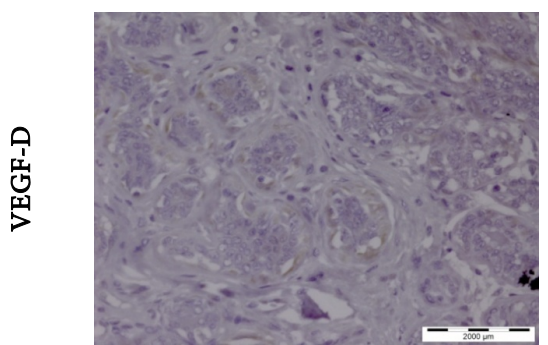

Figure 5(a). Slight immuno-staining of tumour cells in intratumoral area with VEGF-D when treated with citrate AR alone. Original magnification $\times 1000 x$.

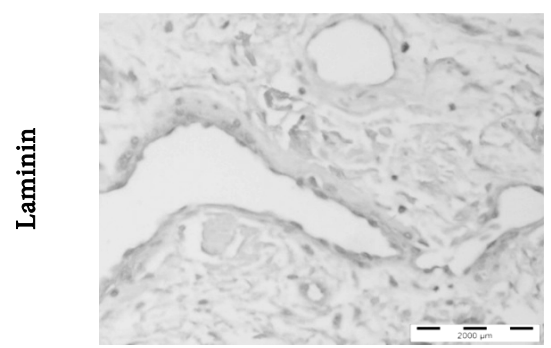

Figure 6(a). Absence of immuno-staining of blood vessels in intratumoral area with laminin when treated with citrate AR alone. Original magnification $\times 1000 x$.

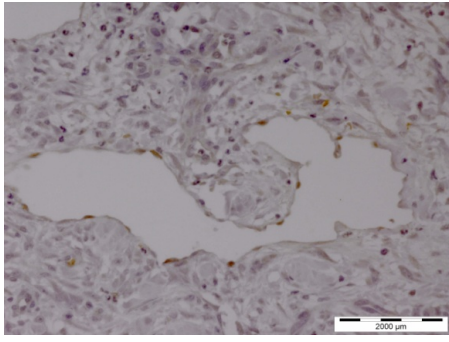

Figure 3(b). Marked nuclear staining in the lymphatic endothelial cells in intratumoral areas with PROX 1 when treated with citrate followed by Tris-EDTA AR. Original magnification $\times 1000 x$.

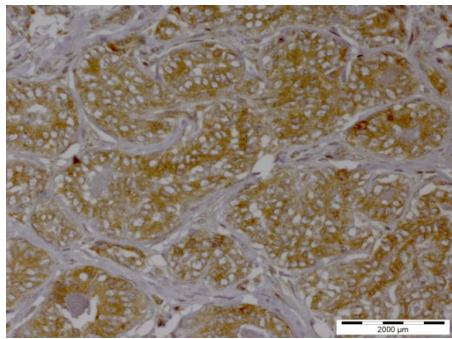

Figure 4(b). Prominent cytoplasmic and mild Figure 4(c). Marked immuno-reactivity but nuclear staining in the intratumoral area with loss of structural and cellular details of tumour VEGFR-3 when treated with citrate followed by Tris-EDTA AR. Original magnification $x$ 1000x.

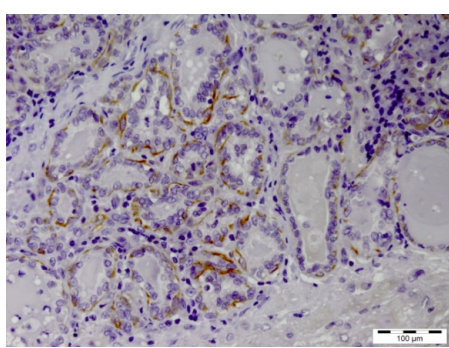

Figure 5(b). Moderate granular cytoplasmic immuno-staining of neoplastic cells with VEGF-D when treated with citrate followed by Tris-EDTA AR. Original magnification $x$ 1000x.

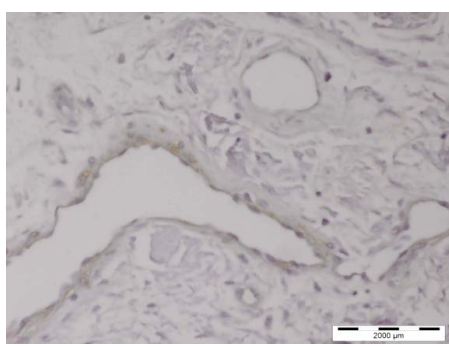

Figure 6(b). Absence of immuno-staining of blood vessels in intratumoral area with laminin when treated with citrate followed by Tris-EDTA AR. Original magnification $x$ 1000x.

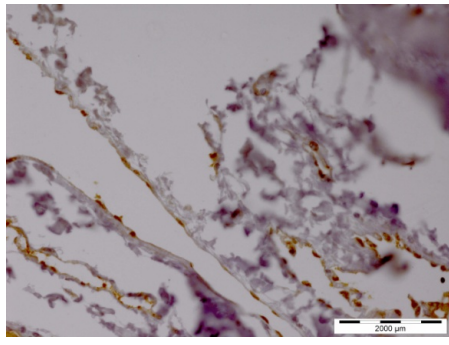

Figure 3(c). Loss of cellular details in CMT for PROX 1 when subjected to citrate,

followed by Tris-EDTA and pepsin treatment.

Original magnification $\times 1000 x$.

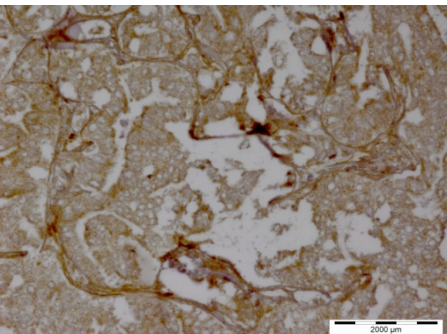

cells with VEGFR-3 when subjected to citrate, followed by Tris-EDTA and pepsin treatment. Original magnification $\times 1000 x$.

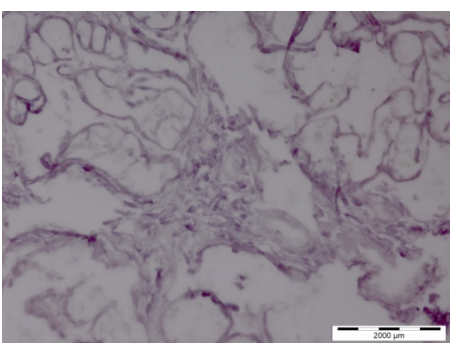

Figure 5(c). Marked immuno-reactivity of tumour cells but loss of structural and cellular details, with VEGF-D when subjected to citrate, followed by Tris-EDTA and pepsin treatment. Original magnification $\times 1000 x$.

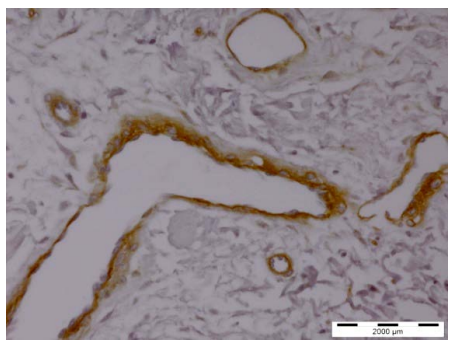

Figure 6(c). Marked immuno-staining of blood vessels in intratumoral area with laminin when subjected to citrate, followed by Tris-EDTA and pepsin treatment. Original magnification $\times 1000 x$. 


\section{Continued}

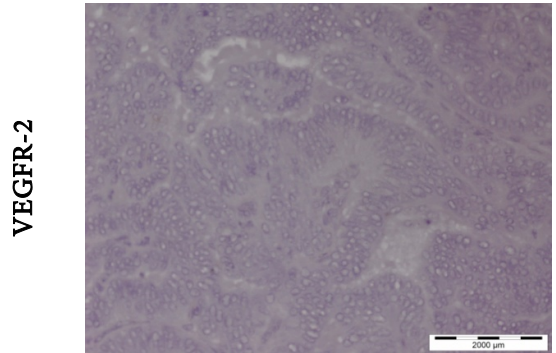

Figure 7(a). Very mild immuno-staining of tumour cells in intratumoral area with VEGFR-2 when treated with citrate AR alone. Original magnification $\times 1000 x$.

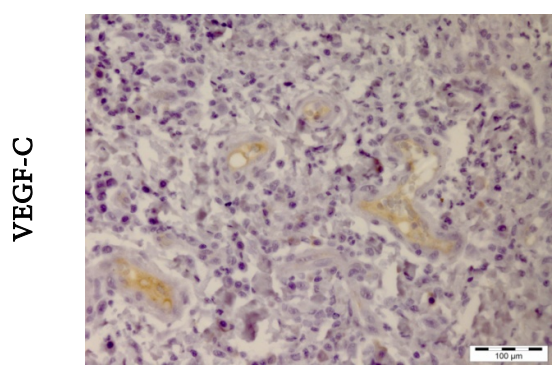

Figure 8(a). Absence of immuno-staining in intratumoral area with VEGF-C when treated with citrate AR alone. Original magnification $\times 100 x$.

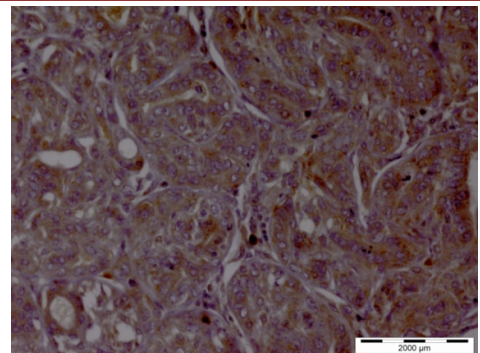

Figure 7(b). Prominent cytoplasmic and nuclear staining in the intratumoral area with VEGFR-2 when treated with citrate followed by Tris-EDTA AR. Original magnification $x$ 1000x.

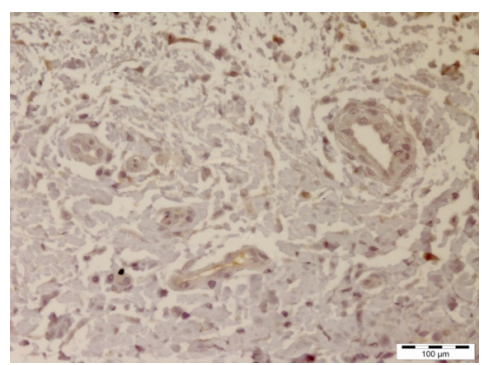

Figure 8(b). Absence of immuno-staining of in intratumoral area with VEGF-C when treated with citrate followed by Tris-EDTA AR. Original magnification $\times 100 x$.

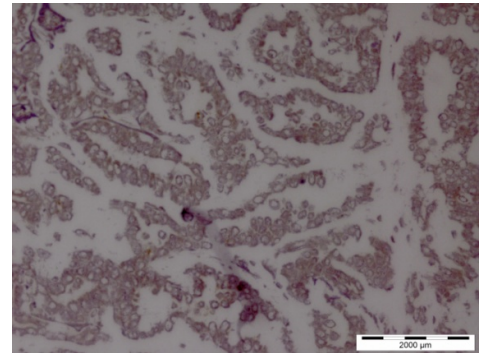

Figure 7(c). Marked immuno-reactivity but loss of structural and cellular details of tumour cells with VEGFR-2 when subjected to citrate, followed by Tris-EDTA and pepsin treatment. Original magnification $\times 1000 x$.

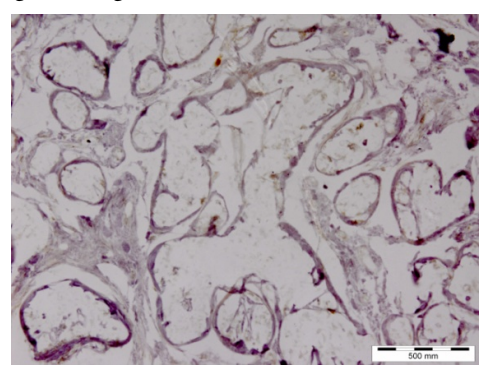

Figure 8(c). Marked loss of cellular details in intratumoral area with VEGF-C when subjected to citrate, followed by Tris-EDTA and pepsin treatment. Original magnification $\times 400 x$.

\section{Discussion}

Dogs with spontaneously arising CMT's are considered a promising animal model of human breast cancer [20] [21] and hence may prove useful for designing trials related to anti-angiogenic and anti-lymphangiogenic therapies. To be used in such comparative oncology studies, blood and lymphatic vessels in CMTs must be identified and differentiated from each other unambiguously. The ideal immuno-histochemical marker for these purposes should have a higher sensitivity and specificity, high repeatability, show low background staining, detect and differentiate both canine blood and lymphatic vessels during disease progression [22].

Till now only few studies have used angiogenic markers in study of CMT's but to the best of our knowledge, no studies relating to lymphatic vessels in CMT's have been documented [23]. Further, no standardized method has been designed till now for AR for the above mentioned markers of angiogenesis and lymphangiogeneisis in CMT's.

One of the basic and important aims of immunohistochemistry is efficient retrieval of antigen. Most of the pathologists use formaldehyde as universal fixative for tissue samples in diagnostic pathology as it's inexpensive and produces good morphological details. The major effect introduced by aldehyde fixation is the 
cross-linking of protein amino acid residues by methylene bridge [24] thus altering the protein secondary, tertiary and quaternary structures, hence lowering the accessibility of antigen sites [25]. Further, aldehyde fixation induces formation of cage-like calcium complexes which require chelating agents like EDTA for reversal conformation of antigens. Thus, the biggest challenge of IHC is to develop standardized methods that perfectly reverse the conformational changes produced during aldehyde fixation and approximately $85 \%$ of Antigens fixed in formalin require some type of AR to optimize the immunoreactions [26] [27].

Most of our CMT samples were very old and over fixed and only a meagre samples exhibited AR through normally followed AR solution i.e. citrate buffer [Figure 1(a), Figure 2(a), Figure 3(a), Figure 4(a), Figure 5(a), Figure 6(a), Figure 7(a), Figure 8(a)] [10] [17]. Further longer fixation times are tend to decrease immuno-reactivity and might require longer, harsher AR methods, increased antibody concentrations or longer primary antibody incubation times to achieve a similar degree of immuno-reactivity [26] [27]. So in order to achieve higher AR percentage, we tried the various combinations [Table 3, Figures $1(\mathrm{a})-8(\mathrm{c})]$.

In the past studies most of the research workers have either used cooker or microwave for AR but in our study we had used a dedicated standard equipment i.e. EZ-Retrieval system, wherein a combination of fixed temperature for a stipulated time was applied (Table 1) to retrieve antigens. The combination of heat and microwave along with AR solution resulted in higher antibody affinity. The heat causes unmasking of epitopes, which was earlier induced by formalin fixation of tissues [28]. Microwave further cause denaturation of the secondary and tertiary structures of proteins [29] and can alter the non-covalent bonding of proteins [7], resulting in higher antibody binding. Hopwood et al. [30] reported that the mechanism of microwave AR is exclusively due to heat. On the contrary, Stone et al. [31] demonstrated that the retrieving effect is caused solely by the microwave oscillating electromagnetic field. Thus, a combined effect of heat and microwaves may have led to higher antibody reactivity in our study.

Use of enzymatic treatment enhanced immunoreactivity for lamnin [32] [Figure 6(c)]. Enzymatic treatment causes the disruption of the crosslinks between the epitopes and the fixative molecules, which have modified the structures of the protein [33]. The enzymatic treatment immuno-reactivity is further enhanced by presence of number of lysine, arginine or asparagine amino acid residues [33], and since laminin is rich in such amino acid residues [34], higher immuno-reactivity was observed with pepsin treatment. No retrieval of laminin antigen was possible by either use of citrate [Figure 6(a)] alone or citrate followed by EDTA buffer [Figure 6(b)], as was also described by Yamashita et al. [35] On contrary, van Hecke [36] reported some of antigens may be destroyed by this enzymatic treatment and will not show any reactivity, as happened with the Podoplanin [Figure 1(c)], LYVE-1 [Figure 2(c)], PROX 1 [Figure 3(c)], VEGFR-3 [Figure 4(c)], VEGF-D [Figure 5(c)] and VEGFR-2 [Figure 7(c)] in 
our study.

Ehara et al. [37] suggested that for most Antigens, HIER with sodium citrate buffer will give satisfactory results and good cell morphology when compared with buffers with higher $\mathrm{pH}$ such as Tris-EDTA. Kim et al. [38] stated that the basic buffer solution like Tris-EDTA seems to be more efficient in retrieving antigens than citrate buffer. Further, as reported by Shi et al. [39] that some antigens will be retrieved with low $\mathrm{pH}$ solutions, others with only high $\mathrm{pH}$ solutions; a third group will be retrieved with solutions with a wide $\mathrm{pH}$ range.

Most of our samples didn't yielded any significant AR for lymphangiogenesis and angiogenesis markers with sodium citrate buffer alone [17] [Figure 1(a), Figure 2(a), Figure 3(a), Figure 4(a), Figure 5(a), Figure 6(a), Figure 7(a), Figure 8(a)]. Shi et al. [40] compared the retrieval of antigen in sections fixed for shorter periods ( 6 hours) and longer periods (30 days) and found that as the tissue is fixed for longer periods, the antigen unmasking becomes difficult, thus compelling us to try different combinations of antigen retrieval in our study as most of our samples were over-fixed. We used a combination of citrate and Tris-EDTA [Figure 1(b), Figure 2(b), Figure 3(b), Figure 4(b), Figure 5(b), Figure 6(b), Figure 7(b), Figure 8(b)] and subjected our antigens to harsher acidic and basic $\mathrm{pH}$ treatment as suggested by Hayat [8], and van Everbroeck et al. [41] that sometimes multiple AR methods in combinations are needed to optimize the immuno-detection of antigens [Table 3, Figures 1(a)-8(c)].

\section{Conclusion}

Efficient AR is overseen by many factors and sometimes single AR does not yield substantial results, so a combination of antigen retrievals can lead to efficient AR. Further as most of our markers for study of lymphangiogenesis and angiogenesis in CMTs have not been utilized too much in animal pathological studies till now, we suggest that during the retrieval of these antigens from CMTs tissues especially old or over fixed tissues, combination of antigen retrievals as suggested in the methodology should be vexed. The immuno-staining intensity for these over fixed, old samples will go on decreasing when compared with the freshly fixed samples.

\section{Acknowledgements}

The authors are thankful to Director of Research, Guru Angad Dev Veterinary and Animal Sciences University, Ludhiana, Punjab, India for providing facilities to carry out the research.

\section{Conflict of Interest}

The authors declare that they have no conflict of interest.

\section{Ethical Approval}

This study did not require official or institutional ethical approval. 


\section{References}

[1] Taylo, C.R. and Kledzik, G. (1981) Immunohistologic Techniques in Surgical Pathology-A Spectrum of "New" Special Stains. Hum Pathology, 12, 590-596. https://doi.org/10.1016/S0046-8177(81)80041-X

[2] MacIntyre, N. (2001) Unmasking Antigens for Immunohistochemistry. British Journal of Biomedical Science, 58, 190-196.

[3] Sheriffs, I.N., Rampling, D. and Smith, V.V. (2001) Paraffin Wax Embedded Muscle Is Suitable for the Diagnosis of Muscular Dystrophy. Journal of Clinical Pathology, 54, 517-520. https://doi.org/10.1136/jcp.54.7.517

[4] van den Berg, F.M., Baas, I.O., Polak, M.M. and Offerhaus, G.J.A. (1993) Detection of p53 Overexpression in Routinely Paraffin-Embedded Tissue of Human Carcinomas Using a Novel Target Unmasking Fluid. American Journal of Pathology, 142, 381-385.

[5] Shi, S.R., Cote, R.J. and Taylor, C.R. (1997) Antigen Retrieval Immunohistochemistry: Past, Present, and Future. Journal of Histochemistry \& Cytochemistry, 45, 327-343. https://doi.org/10.1177/002215549704500301

[6] Trishe, Y.M., Leong, A.S. and Leong, Y. (2007) How Does Antigen Retrieval Work? Advances in Anatomic Pathology, 14, 129-131.

https://doi.org/10.1097/PAP.0b013e31803250c7

[7] Leong, A.S. and Sormunen, R.T. (1998) Microwave Procedures for Electron Microscopy and Resin Embedded Sections. Micron, 29, 397-409. https://doi.org/10.1016/S0968-4328(98)00018-3

[8] Hayat, M.A. (2002) Factors Affecting Antigen Retrieval. In: Hayat, M.A., Ed., Microscopy, Immunohistochemistry and Antigen Retrieval Methods for Light and Electron Microscopy, Kluwer Academic, New York, 53-69.

[9] Imam, S.A., Young. L., Chaiwun. B., et al. (1995) Comparison of Two Microwave Based Antigen-Retrieval Solutions in Unmasking Epitopes in Formalin-Fixed Tissue for Immunostaining. Anti-Cancer Research, 15, 1153-1158.

[10] Kaneko, M.K., Nakamura, T., Honma, R., et al. (2017) Development and Characterization of Anti-Glycopeptide Monoclonal Antibodies against Human Podoplanin, Using Glycan-Deficient Cell Lines Generated by CRISPR/Cas9 and TALEN. Cancer Medicine, 6, 382-396. https://doi.org/10.1002/cam4.954

[11] Becker, J., Wang, B., Pavlakovic, H., Buttler, K. and Wilting, J. (2010) Homeobox Transcription Factor Prox1 in Sympathetic Ganglia of Vertebrate Embryos: Correlation with Human Stage 4s Neuroblastoma. Pediatric Research, 68, 112-117. https://doi.org/10.1203/PDR.0b013e3181e5bc0f

[12] Molhoek, K.R., Erdag, G., Rasamny, J.K., et al. (2011) VEGFR-2 Expression in Human Melanoma: Revised Assessment. International Journal of Cancer, 129, 2807-2815. https://doi.org/10.1002/ijc.25963

[13] Loukovaaraa, S., Gucciardoc, E., Repoc, P., et al. (2015) A Case of Abnormal Lymphatic-Like Differentiation and Endothelial Progenitor Cell Activation in Neovascularization Associated with Hemi-Retinal Vein Occlusion. Case Reports in Ophthalmology, 6, 228-238. https://doi.org/10.1159/000437254

[14] Li, J.C., Li, Y., Ai, J.Y., et al. (2014) Podoplanin Positive Cancer Cells at the Edge of Esophageal Squamous Cell Carcinomas Are Involved in Invasion. Molecular Medicine Reports, 10, 1513-1518. https://doi.org/10.3892/mmr.2014.2338

[15] Laitinen, A., Boeckelman, C., Hagstroem, J., et al. (2017) High PROX1 Expression in Gastric Cancer Predicts Better Survival. PLoS ONE, 12, 1-10. 
https://doi.org/10.1371/journal.pone.0183868

[16] Holzer, T.R., Fulford, A.D., Nedderman, D.M., et al. (2013) Tumor Cell Expression of Vascular Endothelial Growth Factor Receptor 2 Is an Adverse Prognostic Factor in Patients with Squamous Cell Carcinoma of the Lung. PLOS ONE, 8, 1-15. https://doi.org/10.1371/journal.pone.0080292

[17] Loukovaara, S., Gucciardo, E., Repo, P., et al. (2015) Indications of Lymphatic Endothelial Differentiation and Endothelial Progenitor Cell Activation in the Pathology of Proliferative Diabetic Retinopathy. Acta Ophthalmologica, 93, 512-523. https://doi.org/10.1111/aos.12741

[18] Leong, A.S.Y. (2004) Quantitation in Immunohistology: Fact or Fiction? A Discussion of Variables That Influence Results. Applied Immunohistochemistry \& Molecular Morphology, 12, 1-7. https://doi.org/10.1097/00129039-200403000-00001

[19] Bancroft, J.D. and Gamble, M. (2008) Theory and Practice of Histological Techniques. 6th Edition, Churchill Livingstone, Elsevier, London.

[20] Lavalle, G.E., Bertagnolli, A.C., Tavares, W.L. and Cassali, G.D. (2009) Cox-2 Expression in Canine Mammary Carcinomas: Correlation with Angiogenesis and Overall Survival. Veterinary Pathology, 46, 1275-1280.

https://doi.org/10.1354/vp.08-VP-0226-C-FL

[21] Queiroga, F.L., Raposo, T., Carvalho, M.I., Prada, J. and Pires, I. (2011) Canine Mammary Tumours as a Model to Study Human Breast Cancer: Most Recent Findings. In Vivo, 25, 455-465.

[22] Baluk, P. and McDonald, D.M. (2008) Markers for Microscopic Imaging of Lymphangiogenesis and Angiogenesis. Annals of the New York Academy of Science, 1131, 1-12. https://doi.org/10.1196/annals.1413.001

[23] Sleeckx, N., van Brantegem, L., Fransen, E., et al. (2013) Evaluation of Immunohistochemical Markers of Lymphatic and Blood Vessels in Canine Mammary Tumours. Journal of Comparative Pathology, 148, 307-317.

https://doi.org/10.1016/j.jcpa.2012.09.007

[24] Fox, C.H., Johnson, F.B., Whiting, J. and Roller, P.P. (1985) Formaldehyde Fixation. Journal of Histochemistry \& Cytochemistry, 33, 845-853. https://doi.org/10.1177/33.8.3894502

[25] Dapson, R.W. (1993) Fixation for the 1990's: A Review of Needs and Accomplishments. Biotechnic \& Histochemistry, 68, 75-82. https://doi.org/10.3109/10520299309104670

[26] Ramos-Vara, J.A. and Beissenherz, M. (2000) Optimization of Immunohistochemical Methods using Two Different AR Methods on Formalin-Fixed, Paraffin-Embedded Tissues: Experience with 63 Markers. Journal of Veterinary Diagnostic Investigation, 12, 307-311. https://doi.org/10.1177/104063870001200402

[27] Ramos-Vara, J.A. and Miller, M.A. (2014) When Tissue Antigens and Antibodies Get along: Revisiting the Technical Aspects of Immunohistochemistry-The Red, Brown, and Blue Technique. Veterinary Pathology, 51, $42-87$. https://doi.org/10.1177/0300985813505879

[28] Volkin, D.B and Klibanov, A.M. (1989) Minimizing Protein Inactivation. In: Creighton, T.E., Ed., Protein Function. A Practical Approach, IRL Press, Oxford, $1-24$.

[29] Dill, K.A and Shortle, D. (1991) Denatured States of Proteins. Annual Review of Biochemistry, 60, 795-825. https://doi.org/10.1146/annurev.bi.60.070191.004051

[30] Hopwood, D., Yeaman, G. and Milne, G. (1988) Differentiating the Effects of Mi- 
crowave and Heat on Tissue Proteins and Their Cross Linking by Formaldehyde. The Histochemical Journal, 20, 341-346. https://doi.org/10.1007/BF01002727

[31] Stone, J.R., Walker, S.A. and Povlishock, J.T. (1999) The Visualization of a New Class of Traumatically Injured Axons through the Use of a Modified Method of Microwave Antigen Retrieval. Acta Neuropathologica, 97, 335-445. https://doi.org/10.1007/s004010050996

[32] Agboola, A.O.J., Ebili, H.O., Iyawe, V.O., et al. (2016) Tumour Cell Membrane Laminin Expression Is Associated with Basal-Like Phenotype and Poor Survival in Nigerian Breast Cancer. The Malaysian Journal of Pathology, 38, 83-92.

[33] Leenen, P.J.M., Jansen, A. and van Ewijk, W. (1985) Techniques in Immunocytochemistry. In: Bullock, G.R. and Petrusz, P., Eds., Fixation Parameters for Immunocytochemistry: The Effect of Glutaraldehyde or Paraformaldehyde Fixation on the Preservation of Mononuclear Phagocyte Differentiation Antigens, Academic Press, London, 1-24.

[34] D’Alessandro, D., Mattii, L., Moscato, S., et al. (2000) Immunohistochemical Demonstration of the Small GTPase RhoA on Epoxy-Resin Embedded Sections. Micron, 35, 287-296. https://doi.org/10.1016/j.micron.2003.10.001

[35] Yamashita, S. and Okada, Y. (2005) Application of Heat-Induced Antigen Retrieval to Aldehyde-Fixed Fresh Frozen Sections. Journal of Histochemistry \& Cytochemistry, 53, 1421-1432. https://doi.org/10.1369/jhc.4A6579.2005

[36] Van Hecke, D. (2002) Routine Immunohistochemical Staining Today: Choices to Make, Challenges to Take. Journal of Histotechnology, 25, 45-54.

https://doi.org/10.1179/his.2002.25.1.45

[37] Ehara, H., Deguchi, T., Koji, T., et al. (1996) Autoclave Antigen Retrieval Technique for Immunohistochemical Staining of Androgen Receptor in Formalin-Fixed Paraffin Sections of Human Prostate. Acta Histochemica et Cytochemica, 29, 311-318. https://doi.org/10.1267/ahc.29.311

[38] Kim, S.H., Kook, M.C. and Song, H.G. (2004) Optimal Conditions for the Retrieval of CD4 and CD8 Antigens in Formalin-Fixed, Paraffin-Embedded Tissues. Journal of Molecular Histology, 35, 403-408. https://doi.org/10.1023/B:HIJO.0000039856.43632.66

[39] Shi, S.R., Imam, S., Young, L., Cote, R.J. and Taylor, C.R. (1995) Antigen Retrieval Immunohistochemistry under the Influence of $\mathrm{pH}$ using Monoclonal Antibodies. Journal of Histochemistry \& Cytochemistry, 43, 193-201. https://doi.org/10.1177/43.2.7822775

[40] Shi, S.R., Liu, C. and Taylor, C.R. (2007) Standardisation of Immunochemistry for Formalin-Fixed, Paraffin-Embedded Tissue Sections Based on Antigen-Retrieval Technique: From Experiments to Hypothesis. Journal of Histochemistry \& Cytochemistry, 55, 105-109. https://doi.org/10.1369/jhc.6P7080.2006

[41] Van Everbroeck, B., Pals, P., Martin, J.J. and Cras, P. (1999) Antigen Retrieval in Prion Protein Immunohistochemistry. Journal of Histochemistry \& Cytochemistry, 47, 1465-1470. https://doi.org/10.1177/002215549904701112 